EGU21-14921

https://doi.org/10.5194/egusphere-egu21-14921

EGU General Assembly 2021

(c) Author(s) 2021. This work is distributed under

the Creative Commons Attribution 4.0 License.

\title{
Tectonic escape of Sicily Microplate in the context of Africa-Europe collision
}

\author{
Giulia Penza ${ }^{1}$, Pietro Paolo Pierantoni ${ }^{1}$, Chiara Macchiavelli ${ }^{2}$, and Eugenio Turco ${ }^{1}$ \\ ${ }^{1}$ Università di Camerino, Geology Division, Corridonia, Italy (giulia.penza@unicam.it) \\ ${ }^{2}$ Group of Dynamics of the Lithosphere (GDL), Geosciences Barcelona, Geo3Bcn - CSIC, Lluís Solé Sabarís s/n, 08028 \\ Barcelona, Spain
}

Sicily is in the centre of an area where complex geodynamic processes work together, these are: the Tyrrhenian-Apennine System evolution, the African-Ionian slab subduction and Africa-Europe collision.

During the last $5 \mathrm{Ma}$ it was involved in a process of escape towards east-southeast: while on one side Africa acted as an intender pushing toward north, on the other side the fragmentation and retreat of the African-Ionian slab created space to the east.

The aim of this study is to reconstruct the kinematic evolution of Sicily, here considered as an independent plate starting from $5 \mathrm{Ma}$ ago, and its role in the context of the Tyrrhenian-Apennine system.

The plates and microplate involved in the evolution are Europe, Africa and Calabria. The boundaries between these and Sicily are the margin of the Sicily microplate and are lithospheric structures known from the literature and identifiable from high resolution bathymetric maps, seismic sections, geodetic data, focal mechanism of recent earthquakes, gravimetric maps, lithosphere thickness maps and so on.

Briefly the margin between Sicily and Europe is along the Elimi chain, a E-W trending morphostructure with transpressive kinematics, the margin with Calabria microplate is along the rightlateral Taormina line and the margin with Africa is expressed along the Malta Escarpment, south of Etna Mount, with transpressive kinematics and along the Sicily Channel, where a series of troughs (Pantelleria, Linosa and Malta) were interpreted in literature as pull-apart basins related to a dextral trascurrent zone.

The Euler pole of rotation between Sicily and Africa was found starting from the structures in the Sicily Channel and using the GPlates software, then we were able to find also Sicily-Europe and Sicily-Calabria poles and the respective velocity vectors and to compare these with the geological data and better refine the model. 